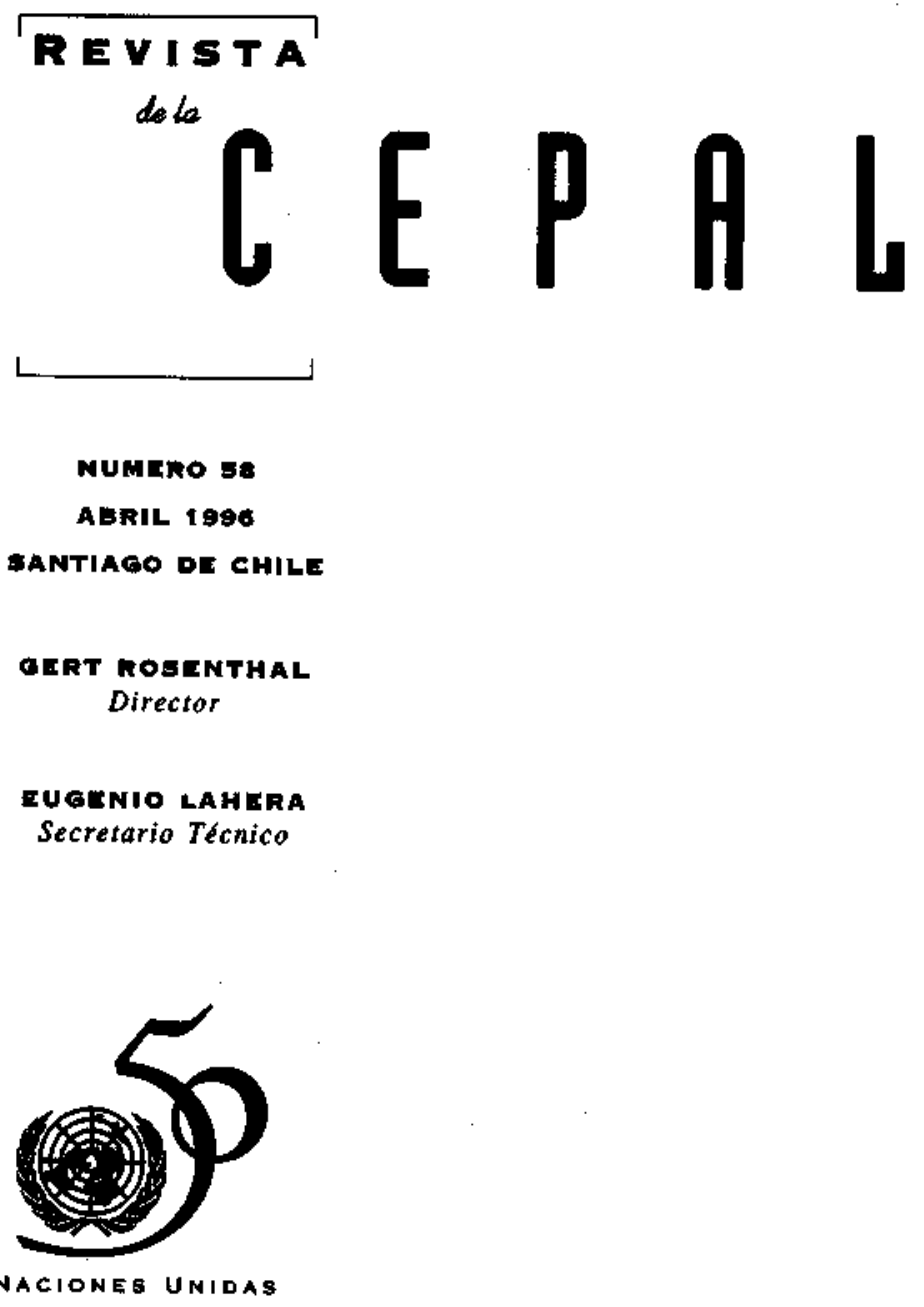




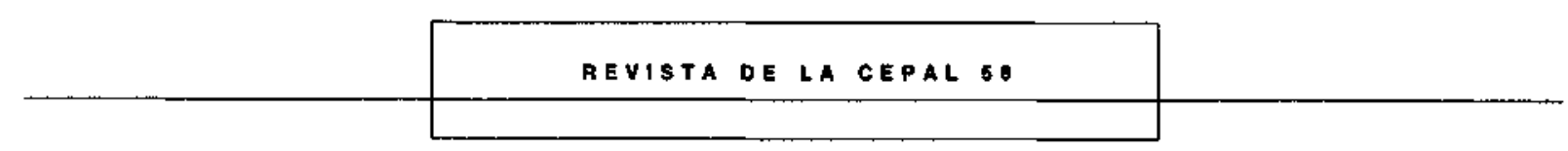

SU MAR I

Anibal Pinto Santa Cruz

7

Gert Rosenthal

Los paradigmas de la política social en América Latina

9

Rolando Franco

Virtudes y limitaciones de los mapas censales de carenclas crficas

Rubén Kaztman

Centroamérica: Infiación y estabilización en la crisis y poscrisis

Hubert Escaith, Claudia Schatan

El Estado, la empresa y la restauración del paradigma neoclásico

A. Barros de Castro

Globalización y pérdida de autonomía de las autoridades fiscales, bancarias y monetarias

Juan Carlos Lerda

El contexto macroeconómico y la inversión: América Latina

a partir de 1980

Graciela Moguillansky

Los derechos de propiedad y el mercado de la tierra rural en América Latina

Frank Vogelgesang

México: Plan y coyuntura

David lbarra

Comercio exterior y medio ambiente: experiencias en tres sectores exportadores chilenos

Imme Scholz

El desafío competitivo para la Industria brasileñe

João Carlos Ferraz, David Kupfer, Lia Hagenauer

Indicadores de la política fiscal: diseño y aplicaciones para Chlle

Ricardo Martner

La CEPAL y la sociología del desarrollo

Enzo Faletto

Orientaciones para los colaboradores de la Revista de la CEPAL 


\section{Indicadores de la política fiscal: diseño y aplicaciones para Chile}

\section{Ricardo Martner}

Dirección de Programación del Sector Público, Instituto Latinoamericano y del Caribe

de Planificación Economica y Social (ItPES)
Las economías de América Latina están sometidas a continuos shocks, tanto de origen externo como interno, to que se traduce en una marcada variabilidad de sus tasas de crecimiento. Es necesario entonces establecer mecanismos de estabilizacion para reducir esta volatilidad, entre los cuales destacan los instrumentos de política fiscal. La variabilidad creciente de las economías lleva a buscar normas de finanzas públicas que presenten características contracíclicas. Estas reglas se basan en la definición de objetivos de mediano plazo del gasto público. congruentes con el crecimiento tendencial de la economía y con su nivel de endeudamiento público, pero independientes del componente cíclico del nivel de actividad. En este esquema, los ingresos tributarios tendrían el rol tradicional de estabilizadores de las fluctuaciones económicas. Como la politica fiscal enfrenta una combinación nefasta de ingresos poco previsibles y gastos rígidos, conviene desarrollar indicadores que distingan los factores transitorios de los elementos permanentes que inciden en las cuentas públicas. En tal sentido, los indicadores de discrecionalidad fiscal ayudan a poner de relieve los problemas de mediano plazo de las finanzas públicas y aplicados al caso de Chile, permiten una medición más precisa de la política fiscal en los últimos años. Esta se ha estructurado en torno a la senda de crecimiento tendencial de la economía, evitando ajustes coyunturales de magnitud. El análisis muestra que, una vez corregido el saldo público de las principales variaciones exógenas de los gastos e ingresos públicos, se observa una orientación más bien restrictiva de la política fiscal, tendiente a controlar la demanda agregada en los años recientes de expansion del nivel de actividad. 


\section{I \\ Introducción}

Algunos episodios recientes se han encargado de recordar, una vez más, la extrema vulnerabilidad de las economías de los países latinoamericanos. Ellas están sometidas a continuos shocks, de origen tanto externo como interno, que causan fuertes variaciones en sus tasas de crecimiento. Históricamente, los ciclos de la relación de precios del intercambio, la volatilidad del flujo de capitales externos y las expansiones no sostenibles del gasto público y privado han generado una marcada inestabilidad en el proceso de desarrollo económico. Además, es probable que las reformas estructurales que efectuaron en los años ochenta la mayoría de los países de la región, como la apertura del mercado de bienes, Ja liberalización y globalización de los mercados financieros y las reformas del mercado del trabajo, acentúen las variaciones del crecimiento y el empleo.

Esta variabilidad de la economía no parece deseable cuando viene acompañada de desequilibrios difíciles de absorber, La menor inversión, el aumento del desempleo y las quiebras de empresas tienen efectos a menudo persistentes en el incremento de las capacidades productivas o de la capacidad de generar empleos productivos. Si se otorga validez a la hipótesis de una cierta histéresis o irreversibilidad en los mercados de capital o de trabajo, es preciso buscar mecanismos e instrumentos que tiendan a reducir la volatilidad señalada. Paradójicamente, la liberalización económica impone importantes desafíos a la capacidad de gestión y de intervención macroeconómica, tanto en los ámbitos monetario y cambiario como en el fiscal. Una importante tarea en los años venideros será la de poner en marcha mecanismos efectivos de intervención que aseguren un grado mínimo de estabilidad en la economía y en las decisiones de consumo y ahorro de los agentes privados y públicos.

En particular, la variabilidad creciente de la economía plantea la necesidad de definir reglas de finanzas públicas con características contracíclicas para suavizar estas fluctuaciones. Las normas de política fiscal se basan, por una parte, en la definición de objetivos a mediano plazo para el gasto público compatibles con la tendencia de crecimiento potencial de la economía y con el nivel de endeudamiento público, pero independientes del componente cíclico del crecimiento; y por otra, en el papel estabilizador de las fluctuaciones económicas que se asigna a los ingresos tributarios. En la región, una de las principales dificultades que enfrentan las autoridades en el manejo de la política fiscal es el contraste entre la vulnerabilidad de sus ingresos y la inflexibilidad de sus gastos. Una forma de enfrentar esta realidad es la de crear instrumentos que permitan separar las decisiones fiscales permanentes de los factores transitorios que inciden en las cuentas públicas. Entre los elementos de carácter coyuntural, destacan por su importancia las fluctuaciones de los precios de las materias primas, la inflación y los ciclos económicos.

Ahora bien, ¿cómo separar las operaciones presupuestarias y tributarias en un componente disctecional, que refleje la dimensión voluntarista de la acción del Estado, y uno automático, que describa los efectos de la coyuntura sobre el presupuesto? Estableciendo indicadores de discrecionalidad, que permitan distinguir el origen exógeno o endógeno del saldo presupuestario. La construcción de indicadores de discrecionalidad fiscal puede resultar muy útil para el diseño de las políticas presupuestarias. Al proporcionar una medida del déficit público independiente del ciclo económico y del ciclo de la relación de precios del intercambio, permite identificar con mayor claridad las decisiones de la autoridad fiscal y calcular la magnitud del déficit que debe ser corregido con medidas discrecionales. En este sentido, los indicadores de discrecionalidad pueden ayudar a poner de relieve los problemas de mediano plazo de las finanzas públicas, a promover un debate informado sobre la política presupuestaria y a reforzar la disciplina fiscal en períodos de auge económico.

En las secciones siguientes de este artículo se examina la conveniencia de establecer normas de gasto público para enfrentar y aminorar las fluctuaciones, promoviendo reglas del juego estables en el mediano y largo plazo, y asegurando la eficacia de la acción pública (sección II); se describen los métodos de elaboración de los principales indicadores de discrecionalidad fiscal, básicamente asociados a los trabajos de la Organización de Cooperación y Desarrollo Económicos y del Fondo Monetario Internacional (sección III); se muestran las estimaciones realizadas en el caso 
de Chile para obtener las elasticidades tributarias y la senda del producto tendencial, elementos que permiten aplicar los indicadores de discrecionalidad (sección IV); se analizan los resultados obtenidos, separando los componentes tendenciales, cíclicos y discrecionales de las finanzas públicas en Chile (sección V), y finalmente, se presenta una síntesis y algunas conclusiones (sección VI).

\section{II \\ ¿Qué norma de gasto público?}

En general, los efectos de la política fiscal se evalúan directamente a partir del saldo presupuestario, de manera que cuando el déficit público aumenta (o el superávit disminuye) se entiende que la política fiscal ha tenido una orientación expansiva, y en caso contrario, contractiva. Esta interpretación resulta excesivamente simplista, puesto que el resultado contable del sector público es determinado tanto por decisiones de las autoridades públicas como por factores que éstas no controlan directamente. El saldo contable del presupuesto es un indicador ambiguo de la política fiscal, ya que refleja a la vez la incidencia de medidas discrecionales emanadas de las autoridades y la influencia de la coyuntura económica en el presupuesto.

En períodos de expansión, los ingresos públicos crecen rápidamente y los gastos asociados a subsidios al desempleo o a sectores económicos tienden a reducirse. Ambos factores ejercen un efecto de compresion sobre el déficit. En cambio, en momentos de recesión económica, el bajo nivel de actividad degrada fuertemente el balance presupuestario, sobre todo si el desempleo es masivo. Aquellos ingresos y gastos públicos cuya evolución se vincula al ciclo económico se denominan estabilizadores automáticos. La importancia de estos estabilizadores varía según los países, reflejando el tamaño del sector público, la progresividad del sistema tributario, la sensibilidad de las bases impositivas a las fluctuaciones de la actividad económica, la generosidad de los esquemas de subsidios al desempleo y la sensibilidad del desempleo a las variaciones del producto.

Por ejemplo, en 1993 los factores cíclicos originaban casi la mitad de los déficit públicos de los países de la Organización de Cooperación y Desarrollo Económicos (OCDE, 1993). El contexto recesivo en estos países -y la agudización de los problemas en sus finanzas públicas- ha producido un resurgimiento de los estudios orientados a caracterizar el compo- nente cíclico del presupuesto. ${ }^{1}$ En el caso de algunos países de América Latina es muy probable que la notable recuperación de las finanzas públicas de los ulltimos años contenga un componente cíclico significativo, habida cuenta de la recuperación de la actividad económica y de los procesos de desinflación que se han registrado en los años recientes. ${ }^{2}$ No es menos relevante entonces elaborar indicadores que proporcionen una visión de mediano plazo del estado de las cuentas públicas en períodos de auge económico.

Por otra parte, en publicaciones recientes se insiste en el concepto de déficit sostenible (Chouraqui, Jones y Montador, 1986; Blanchard, Chouraqui, Hagemann y Sartor, 1990; Buiter, 1988), definido como el déficit primario que asegura la estabilización (o disminución) de la deuda pública como porcentaje del PIB. Este saldo primario es proporcional a la deuda previa y a la diferencia entre la tasa de interés real y la tasa de crecimiento de la economía. Blanchard, Chouraqui, Hagemann y Sartor (1990) proponen indicadores de sostenibilidad fiscal basados en la evolución de la diferencia entre la tasa de interés y la tasa de crecimiento. ${ }^{3}$ Estos indicadores deben tener una dimensión de mediano plazo, puesto que los movimientos cíclicos del piB y las fluctuaciones transitorias de las tasas de interés, aun cuando llevan a un alza temporal de la deuda pública, no implican ni deficit excesivos ni políticas fiscales insostenibles. Por lo tanto, es difícil juzgar la sostenibilidad de las finanzas públicas en períodos muy cortos. Finalmente, algunos autores distinguen, para fines normativos, el componente de regulación del déficit

\footnotetext{
1 Respecto de Espanaa, por ejemplo, vêase Fernández, Nadal y Sanz (1993) y Molinas (1994).

2 A partir de 1992-1993 las tinanzas públicas de la mayoría de los países de América Latina muestran situaciones relativamente controladas (CEPAl. 1994).

3 Véase una aplicación de estos indicadores al caso de México en Martner, 1995.
} 
(Creel y Sterdyiniak, 1995). En determinadas circunstancias, el sector público puede ir más allá del juego espontáneo de los estabilizadores automáticos y practicar políticas discrecionales, estimulando el crecimiento con alzas del gasto público o disminuciones de impuestos no compensadas en un contexto recesivo, 0 , por el contrario, frenando la expansión del nivel de actividad con políticas de ajuste.

Esta descomposición de indicadores de orientación fiscal pone de manifiesto, por una parte, la multiplicidad de objetivos contrapuestos de las autoridades fiscales, y por otra, la dificultad de juzgar con criterios mecánicos el nivel de las cuentas públicas. En tal sentido, no existen criterios sobre lo óptimo en materia de política fiscal; ésta debería orientarse por objetivos macroeconómicos de mediano plazo, y no por objetivos contables. Buscar la eficiencia macroeconómica de la política fiscal supone responder a las dos siguientes preguntas: ¿Cuál es el nivel de producción deseable tomando en cuenta el equilibrio externo, la inflación y la situación financiera de las empresas? Para llegar a ese nivel, ¿debe el sector público practicar una política expansiva o una restrictiva?

En economías de alta variabilidad como las de la región, con restricciones periódicas de financiamiento y dificultades para establecer políticas fiscales activas, es deseable hacer explícitas normas de gasto público a lo largo del ciclo que permitan sostener el crecimiento cuando la economía se sitúa en la parte baja de él y reducir la deuda pública cuando la economía se encuentra en la parte alta del ciclo. El concepto de norma en materia de finanzas públicas puede promover reglas del juego más estables, que el Estado se compromete a respetar a mediano y largo plazo y que contribuyen a asegurar la eficacia de la acción pública. En efecto, sobre la base de estas reglas, los agentes económicos tienen más posibilidades de materializar sus expectativas de consumo e inversión más allá de las fluctuaciones de corto plazo del nivel de actividad. La norma anual no debería referirse ś́lo al saldo público, sino sobre todo al nivel del gasto. Además del carácter marcadamente procíclico de una norma de saldo - cuando una economía entra en recesión, los ingresos y el saldo público se deterioran-, la norma de gasto puede estabilizar las expectativas de los agentes privados, ya que hace más previsible la evolución de la economía, tiende a minimizar las distorsiones generadas por la intervención pública y tiene mayor proximidad con los factores que determinan la utilidad de los agentes privados. En otras palabras, una norma de gasto público sostenible en el tiempo puede ayudar a reducir la volatilidad del nivel de actividad, si existen políticas monetarias y cambiarias que apunten en la misma dirección.

Pero el respeto estricto a una norma restrictiva de gastos es más fácil cuando existen fuertes déficit y políticamente más difícil en caso de excedente o de un déficit pequeño, es decir, en la parte alta del ciclo: para manejar la escasez es necesario primero administrar la abundancia. Es por ello que Ia clara identificación en los déficit y los excedentes del componente coyuntural (vinculado básicamente a los estabilizadores automáticos y al ciclo de la relación de precios del intercambio), y del componente estructural (que afecta el nivel de endeudamiento de largo plazo), puede ayudar a la transparencia de las decisiones presupuestarias.

Si bien la definición de una norma de gasto público a mediano plazo que cubra la duración del ciclo representa una regla sólida para la gestión de las finanzas públicas, las modalidades de formulación de esta norma no son simples. En efecto, la referencia a un ciclo supone conocer su duración y sus límites inferior y superior. Este tipo de indicadores no están exentos de controversia; como se plantea en Blanchard, Chouraqui, Hagemann y Sartor (1990), la duración y naturaleza de los ciclos genera polemica, por lo que el ajuste cíclico del déficit sólo tiene sentido si la economía vuelve a su senda de crecimiento tendencial en un lapso relativamente corto. Por ejemplo, en los países europeos el desempleo se estabiliz6 en los años ochenta a niveles muy superiores a los que existían previamente, y por lo tanto no es seguro que la recuperación económica reduzca el desempleo - y el déficit que implica- a los niveles anteriores.

Una cuestión crucial entonces en este tipo de metodologías, y no exenta de dificultades, es la identificación adecuada del ciclo económico, así como la fase del ciclo en que se encuentra la economía, puesto que no existe una simetría perfecta entre las partes alta y baja del ciclo.

La segunda dificultad se refiere a la definición de la norma. Es evidente que no existen reglas objetivas sobre el gasto. Tres criterios merecerían sin embargo ser tomados en consideración:

a) La norma de gasto público debe ser compatible con la evolución deseada de las finanzas públicas en el período del ciclo. En particular, debe existir compatibilidad en este período entre los ingresos previstos que dependen del crecimiento tendencial a lo largo del ciclo y los gastos públicos de naturaleza permanente. Esto supone la capacidad de determinar el 
ritmo de crecimiento tendencial, ejercicio que es muy complejo en la región, dada la gran variabilidad de sus tasas de crecimiento. En tal sentido, una evaluación realista del crecimiento tendencial de la economía evita que el sector público se transforme en una caja de resonancia de las fluctuaciones económicas y de los ciclos de la relación de precios del intercambio.

b) La norma de gasto público no es independiente del nivel de endeudamiento del sector público. En particular, es necesario asegurarse que en el período del ciclo el nivel de endeudamiento conduzca a una evolución de la deuda que sea sostenible a mediano y a largo plazo. Se razona habitualmente sobre la base de la deuda en relación al PIB; se podría preferir un criterio más próximo al que utilizan los intermediarios financieros para analizar la solvencia de sus deudores, como la relación entre la carga de intereses y los ingresos del Estado. Este indicador contribuye a relativizar la importancia de la deuda según el nivel de las tasas de interés. Permite asimismo precisar el impacto de las reducciones de ingresos sobre la sostenibilidad de la política fiscal.

c) El tercer criterio, y no el menos importante, se distancia de una vision demasiado tecnocrática del problema. Es necesario que la norma sea justificable frente a la opinión pública y el Parlamento, puesto que en realidad es de índole política. No se debe por lo tanto temer a la adopción de normas generales, como la de evolución paralela de los gastos y del pIB nominal o de simple indexacion sobre los precios en un contexto de disminución de la proporción del gasto público en la economía.

Más allá de la definición de una norma satisfact toria, que sería por lo tanto independiente del ciclo económico, la naturaleza de los gastos públicos no se presta fácilmente a este ejercicio. ${ }^{4} \mathrm{La}$ dinámica del par go de intereses, por ejemplo, depende del nivel de endeudamiento y de la evolución de las tasas de interés. Existe por otro lado un núcleo duro en los gastos del Estado que no se presta a reducciones simples cuando ello es necesario. Estos gastos son poco flexibles, ya que se basan en criterios de acceso a menudo muy extendidos que conducen a problemas de crecimiento poco controlados y a un gasto permanente, haciendo imposible una orientación a la baja en caso de mejora coyuntural. El establecimiento de una programación plurianual puede facilitar la imposición de restricciones en un marco más flexible que el ejercicio presupuestario anual (Martin y Núñez del Prado, 1993; Marcel, 1993). Naturalmente, una norma de gasto sólo es posible a partir de una definición explícita de los ingresos esperados a lo largo del ciclo.

\section{III}

\section{Indicadores de orientación de la política fiscal:} aspectos metodológicos

Las variaciones de un gasto o un ingreso del sector público tienen carácter automático cuando responden a factores endógenos al modelo económico y exógenos al sector público, es decir, cuando se trata de variaciones de los componentes del presupuesto que son sensibles a la influencia de los agregados económicos. A la inversa, cuando se trata de variaciones que responden a decisiones de la autoridad pública, éstas son de carácter discrecional. Una primera descomposición del déficit observado distingue entonces entre el déficit automático y el déficit discrecional. Esta distinción no es trivial, puesto que en su origen todos los gastos e ingresos públicos son discrecionales, respondiendo a decisiones del gestor público. Por esto el concepto de discrecionalidad es necesariamente relativo, tiene una dimensión temporal y se plantea como un ejercicio contrafactual. Lo que se intenta por lo tanto es separar, dentro de las variaciones observadas en las partidas de gastos e ingresos públicos, el componente que responde a decisiones controlables por la autoridad del resto del presupuesto. Dadas las posibilidades de ajuste existentes, el criterio de neutralidad o de discrecionalidad fiscal es necesariamente arbitrario, porque depende de las definiciones del investigador.

En una definición restringida, se trata de obtener indicadores de política fiscal independientes del ciclo

\footnotetext{
4 Marcel (1993) calcula que en Chile más del $70 \%$ del gasto público programado está predeterminado legalmente, lo que muestra el grado de inflexibilidad del presupuesto.
} 
económico. El indicador de la ocDE (Gramlich, 1990; OCDE, 1993) separa el déficit en un componente cíclico y en otro estructural. El comportamiento de los gastos e ingresos se expresa en un modelo cuando la economía se aparta de la senda tendencial de crecimiento (recuadro 1). La variación en un ingreso o gasto público tiene carácter cíclico cuando es producida por la diferencia entre el producto observado y el producto tendencial. Es decir, la posición cíclica de la economía lleva a fluctuaciones que se reflejan en el presupuesto, sobre todo en la recaudación tributaria y en el gasto en subsidios de desempleo. El mismo ejercicio puede realizarse para el déficit primario, descon- tándose el componente exógeno correspondiente al pago de intereses de la deuda externa e interna.

Como señala Molinas (1994), este indicador tiene dos ventajas respecto del saldo presupuestario efectivo: por una parte, al proporcionar una medida del déficit público independiente del ciclo económico, permite calificar la orientación que las autoridades económicas han imprimido a la política fiscal en los años pasados; por otra, puesto que el déficit estructural no se corrige automáticamente al recuperarse la senda de crecimiento tendencial tras un período de recesión, el indicador permite identificar la magnitud del déficit que debe ser corregida por medidas discrecionales.

Recuadro 1

EL. INDICADOR ESTRUCTURAL DE LA OCDE

Para obtener el déficit ć́clico, la $\propto$ CDE desagrega el presupuesto en ingresos tributarios, otros ingresos, gastos en prestaciones por desempleo y otros gastos. El componente cíclico de los ingresos tributarios se obtiene a partir de su elasticidad respecto del PIB y de la diferencia existente entre el PIB observado $Y$ y el PIB tendencial $Y^{*}$ en el año $t$ :

$$
\text { Ingresos cíclicos }=T_{j}: \varepsilon_{j} \cdot \frac{Y-Y^{*}}{Y^{*}}
$$

En que $T_{j}$ son los ingresos tributarios observados en $t$, cortespondientes a la categotía $j$ (que se desglosa en impuestos personales, impuestos de sociedades, impuestos indirectos ligados a la producción e importación y cotizaciones sociales y $\varepsilon_{j}$ es la elasticidad-ingreso respecto del P1B, para las diferentes categorias de impuestos $j$. Por lo tanto, para estimar los ingresos cíclicos se requiere estimar las elasticidades-ingreso y el producto tendencial. Por el lado de los gastos, tanto en el indicador de la 0 CDE como en el del FM, se considera que únicamente el gasto en prestaciones por el desempleo tiene un componente cíclico. La formalizacion del modelo parte del supuesto de que la relación entre el gasto en desempleo ććlico y el gasto total en desempleo, y la relación entre la tasa de desempleo cíclico y la tasa de desempleo total, son iguales:

$$
\frac{\text { Gasto en desempleo cíclico }}{\text { Gasto en desempleo total }}=\frac{\text { Tasa de desempleo cíclico }}{\text { Tasa de desempleo total }}
$$

La expresión del gasto cíclico en desempleo es la siguiente: $\frac{\text { Tasa de desempleo cíclico }}{\text { Tasa de desempleo total }}$

Gasto en desempleo ciclico $=($ Gasto en desempleo total $)$

Por su parte, la tasa de desempleo cíclico se obtiene a partir de la diferencia entre el PIB observado y el pIB tendencial.

El indicador del FMI pone de relieve el concepto de neutralidad fiscal, definido por la suma del déficit cíclico y el déficit tendencial. El déficit tendencial se asocia a la evolución de gastos e ingresos según el PIB tendencial (recuadro 2).
La suma del déficit cíclico y del déficit tendencial es lo que el FMI denomina el déficit presupuestario neutro. El indicador del FMI (Heller, Haas y Mansur, 1986; Chand, 1992) se obtiene entonces como la diferencia entre el déficit observado y el déficit presu- 
Recuadro 2

EL INDICADOR DE IMPULSO FISCAL DEL FMI

El indicador del fMt opta por formalizar los déficit cíclico y tendencial, y obtiene el déficit discrecional o impulso fiscal como diferencia con respecto al saldo observado. La principal diferencia entonces con el indicador anterior es que esta vez se modelizan los componentes tendenciales del déficit. Para la modelización de los déficit tendencial y cíclico se elige un año base en que se considere que el piB observado coincide con el PIB tendencial, de manera que un impulso fiscal positivo se interpreta como expansivo en relación al año base. Se supone que los ingresos tendenciales crecen con elasticidad unitaria respecto del PIB tendencial, de modo que representan en el año $t$ la mismá proporción del PIB tendencial que en el afoo base, donde $t_{o}$ es la tasa tributaria del año base:

Ingresos tendenciales $=t_{o}, Y_{\text {, }}^{*}$

Por su parte, los gastos tendenciales, excluyendo las prestaciones por desempleo, se definen de la misma manera, de modo que representan igual proporción del PIB tendencial que en el año base:

$$
\text { Gastos tendenciales }=g_{0} \cdot Y_{t}^{*}
$$

donde $g_{o}$ representa el gasto público en relación con el PlB del año base, excluidos los gastos de desempleo

Se considera que el resto del gasto público sólo tiene componentes tendenciales y discrecionales. Las prestaciones por desempleo se separan en un componente cíclico y otro tendencial. Esta último se define suponiendo que se mantiene en términos reales el subsidio medio por beneficiario, y que el número de beneficiarios crece como la población activa. Los gastos cíclicos en desempleo también se determinan respecto del año base a partir del desempleo cíclico.

Por último, los ingresos cíclicos se obtienen a partir de la diferencia entre el pub observado y el tendencial, manteniendo la razón entre los ingresos y el PtB del año base:

$$
\text { Ingresos cíclicos }-t_{0} \cdot\left[Y_{t} \cdot Y_{t}^{*}\right]
$$

Esta definición implica una elasticidad unitaria de los ingresos cíclicos en relación con el plB observado, lo cual facilita los cálculos respecto del indicador anterior. El criterio de neutralidad fiscal del fMI incluye los ingresos que crecen en referencia al año base con elasticidad unitaria respecto del PBB y los gastos que crecen con elasticidad unitaria respecto del pis tendencial, siempre en relación con el año base. De esta forma, un ingreso es considerado neutro si su tasa de crecimiento coincide con la tasa de crecimiento del piB observado, y un gasto es considerado neutro si su incremento es igual al del PIB tendencial.

puestario neutro, magnitud que también se define como "impulso fiscal". El indicador del FMI opta por separar los deficit cíclico y tendencial —es decir los dos componentes del déficit presupuestario neutro o automático- para obtener de manera indirecta el impulso fiscal como diferencia respecto del deficit observado.

Pero un indicador de política fiscal también puede separar todos los componentes automáticos del déficit, que escapan al control de la autoridad. Esta definición es mucho más amplia, por cuanto incluye, por ejemplo, el efecto de la inflación sobre la recaudación tributaria, el impacto del precio de las materias primas sobre las utilidades de las empresas públicas y el alża de los intereses pagados por incrementos de las tasas de interés o por la devaluación de la moneda nacional. En los indicadores recién descritos de la OCDE y del FMI, por ejemplo, el efecto de la inflación sobre la recaudación tributaria o las variaciones de las tasas de interés o las fluctuaciones del precio de las materias primas producidas por empresas públicas se consideran como variaciones discrecionales del déficit. Esto se debe, sin duda, a la menor importancia relativa de estos mecanismos en los países desarrollados. Como destaca Marcel (1993), la importancia del componente exógeno y particularmente del sector externo en las 
finanzas públicas de los países de América Latina dificulta la identificación precisa del componente discrecional del presupuesto. A la vez, la diversidad de flujos exógenos en las cuentas públicas limita la aplicación de indicadores de política fiscal como los del
FMI O la OCDE. En la sección siguiente se calculan, para el caso de Chile, indicadores de orientación de la política fiscal, excluyendo el componente externo exógeno más significativo en los ingresos públicos del país: las exportaciones de cobre.

\section{IV}

\section{Estimaciones para el caso de Chile}

La aplicación mecánica a los países de América Latina de los indicadores de orientación fiscal descritos puede llevar a resultados poco útiles en países con problemas e instituciones diferentes. Como se expresa en Marcel (1993), entre los requisitos necesarios para que este tipo de indicadores represente una medida adecuada de la política fiscal destacan los siguientes: i) una recaudación tributaria significativa, de manera que el componente cíclico de los ingresos públicos tenga alguna relevancia; ii) una autoridad fiscal unificada, que tenga algún grado de control sobre una proporción importante del gasto público; iii) fuentes exógenas relativamente limitadas de movimientos en las finanzas públicas, y iv) cierto grado de desarrollo del mercado financiero, para que la política fiscal pueda distinguirse de la política monetaria.

En el caso de Chile, la centralización de la autoridad fiscal, las limitaciones al endeudamiento de los municipios, el carácter superavitario de las empresas públicas y la eliminación de las operaciones cuasifiscales en los últimos años permiten evaluar la política fiscal a partir de la contabilidad del gobierno central. Además, por la existencia del Fondo de Compensación del Cobre ( $\mathrm{FCC}$ ), es posible separar de las cuentas públicas los efectos de los movimientos no previstos del precio de este metal.

Debido a la notable disminución de la deuda pública chilena en los últimos años y a la diferencia relativamente moderada entre la tasa de interés real y la tasa de crecimiento de la economía, la referencia a los indicadores de sostenibilidad de la deuda pública no tiene mayor relevancia en el contexto actual. La política fiscal ha sido claramente sostenible en los últimos años y más aún, el sector público ha prepagado montos significativos de su deuda externa cuando ha tenido ingresos considerados como transitorios.

Por otra parte, la incidencia de la inflación sobre la recaudación real es muy limitada, puesto que la mayoría de los impuestos están indexados mensualmente a la variación de precios. La inflación, por lo tanto, no representa una fuente significativa de distorsión de los ingresos tributarios. ${ }^{5}$ Las características reseñadas del sector público en Chile permiten suponer que los indicadores de discrecionalidad representan una medida adecuada de la política fiscal.

La construcción empírica de estos indicadores supone recurrir a la econometría para estimar las elasticidades tributarias y el producto tendencial (recuadro 3). La estimación de la elasticidad de la recaudación está sujeta a los continuos cambios en la estructura tributaria. En Chile, la principal reforma tributaria data de 1975: ella definió los rasgos básicos del nivel y la composición de la carga tributaria (Carcioli, Barris y Cetrángolo, 1994); introdujo el impuesto al valor agregado (IVA), que se transformaría en el eje del sistema, y eliminó numerosos tributos. La posterior reforma de 1984 redujo el impuesto a la renta, restando progresividad al sistema en los impuestos a las personas y disminuyendo los impuestos a las utilidades de las empresas. En 1988, la tasa del IVa bajó de 20 a $16 \%$ y disminuyó nuevamente la tasa aplicada a las utilidades. En 1990, la tasa del IVA aumentó a $18 \%$ y se reforzó la progresividad del sistema mediante el acortamiento de los tramos de ingresos y el incremento de las tasas a las utilidades devengadas. Finalmente, la reforma de 1993 contempló reducciones graduales de la tasa del rva y cambios en los tramos de ingreso.

Por otra parte, una fuente de recaudación importante son los impuestos a productos específicos, en

\footnotetext{
5 En cambio, la infiación sí tiene incidencia en el gasto público real en el corto plazo, básicamente por el régimen anual de indexación de los salarios y pensiones pagados por el sector público. Así, cuando la inflación aumenta se genera un superávít público de corto plazo, lo que representa un importante mecanismo de estabilización fiscal (Marcel, 1991).
} 
Recuadro 3

Chile: Estimación de la functón tributaria y del producto tendencial

Para calcular los indicadores de discrecionalidad fiscal es preciso estimar econométricamente la elasticidadingreso de la recaudacion tributaria y el producto potencial.

\section{Estimación de una función tributaria agregada}

La recaudación tributaria anual $T$ se estima en función del PiB $(Y)$ y de sus propios valores rezagados para el período 1976-1993. Las minúsculas denotan logaritmos, y los valores entre paréntesis son los $T$ de Student. Se introducen además dos variables ficticias que modifican el valor de la constante para los períodos 19841987 y $1988-1990$ :

$$
\begin{aligned}
& t=-5.82+1.11 \mathrm{y}+0.25 t_{1}+0.067 D 84-87 \cdot 0.10 D 88-90 \\
& \begin{array}{llll}
-(14.7) & (16.0) & (4.77) & (5.01)
\end{array}
\end{aligned}
$$

$R^{2}=0.99, \sigma=0.022, D W=2.15, N\left(\chi^{2}\right)=0.16, A R 1-2 F(1,11)=1.55, A R C H F(1,11)=0.53$, RESET $F(1,13)=0.03$

La estimación tiene propiedades estadísticas adecuadas: no se detecta autocorrelación de errores (pruebas DW y AR 1-2), hay normalidad (el resultado de la prueba $N\left(\chi^{2}\right)$ es cercano a cero) y homoscedasticidad (prueba $A R C H$ ) en los residuos, y no existen problemas de especificación funcional (prueba RESET). La elasticidad-ingreso de corto plazo es de 1.11 y la de largo plazo de 1.49. Esto significa que los ingresos tributarios fluctúan con el PIB de manera más que proporcional. El rezago medio de la ecuación es de 1.5 años, que refleja el plazo de la recaudación tributaria.

\section{Estimación del producto tendencial}

El cálculo de la senda tendencial del PIB se basa en la metodología de la ఎCDモ de tendencias truncadas (Gramlich, 1990). Esta consiste simplemente en estimar coeficientes de crecimiento tendencial diferentes para distintos períodos. El método permite separar de manera sencilla los componentes cíclico y tendencial del producto. La regresión del PiB contra distintas tendencias en el período 1976-1993 entrega los siguientes resultados:

$$
\begin{gathered}
y=11.2+0.0618 \text { Trend } \\
(240.1) \\
(39.2)
\end{gathered}
$$

$R^{2}=0.99, \sigma=0.017, D W=1.97, N\left(\chi^{2}\right)=0.82, A R 1-2 F(2,11)=1.53, A R C H F(1,30)=1.19, R E S E T F(1,12)=0.29$

La variable Trend $_{76-81}$ toma el valor de la tendencia entre 1976 y 1981 y 0 en el resto de la muestra; las variables $D 82$ y $D 83$ toman el valor 1 en 1982 y 1983 respectivamente y 0 en los restantes períodos. Se obtiene una tasa de crecimiento tendencial de $6.2 \%$ entre 1984 y 1993 , valor que asciende a más de $7.5 \%$ para los años 1976-1981. Las pruebas estadísticas muestran una estimación adecuada, con ausencia de autocorrelación y normalidad de los residuos.

particular los combustibles, cuyas tasas se han comportado de manera procíclica, aumentando en períodos de recesión para cubrir las disminuciones de recaudación del IVA y disminuyendo en períodos de expansión. Por último, las sucesivas reformas comerciales han reducido y uniformado las tasas arancelarias, mermando el peso relativo de estos impuestos en la estructura tributaria.
La mayor dificultad que existe para estimar las funciones tributarias son los frecuentes cambios en la política tributaria, tanto en lo que se refiere a tasas y bases como a la progresividad del sistema. Una forma de abordar este problema es estimando coeficientes variables, mediante el método de filtros de Kalman. El método utilizado aquí es diferente, pues hace uso de variables ficticias para dar cuenta de los cambios 
producidos por las reformas tributarias (recuadro 3). Las estimaciones muestran que las reformas tributarias recientes han afectado principalmente el nivel de la recaudación (lo que se refleja en los cambios en el intercepto de la ecuación), pero no tanto la progresividad del sistema (medida por la elasticidad-ingreso) ni los plazos de recaudación (Martner, 1995). La elasticidad tributaria que se obtiene a corto plazo es superior a uno, lo que muestra que la recaudación es muy sensible a los ciclos económicos.

Al estimar el producto tendencial, se obtiene una tasa de crecimiento medio anual de $6.2 \%$ entre 1984 y 1993. La sostenibilidad de una tasa de crecimiento tendencial tan alta es discutible, aunque corresponde a la evolución de la economía chilena en los últimos diez años. Esto implica que tasas de crecimiento diferentes a esta media son consideradas como cíclicas e inciden en el cálculo de ingresos y gastos automáticos. Por ejemplo, una tasa de crecimiento inferior al $6 \%$ supone ingresos cíclicos negativos.

Los residuos de la ecuación estimada (gráfico 1) muestran la evolución del ciclo en torno a la tendencia, o diferencia entre el producto efectivo y el tendencial. Se observa que el PIB se mantuvo por debajo de su tendencia en los años 1990-1991, como consecuencia del ajuste de 1990, y se situó por encima en los dos últimos años a rá́z del fuerte crecimiento de 1992. En 1994 el crecimiento fue de $4 \%$, lo que hace suponer que la diferencia entre uno y otro producto resultó negativa para dicho año. Disponemos ya de los coeficientes requeridos para estimar los ingresos tributarios ć́clicos.

GRAFICO I

Chile: Producto tendencial y producto efectivo

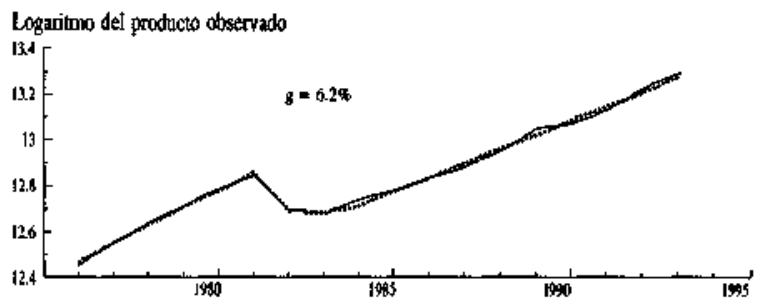

Resideos de la ecuación

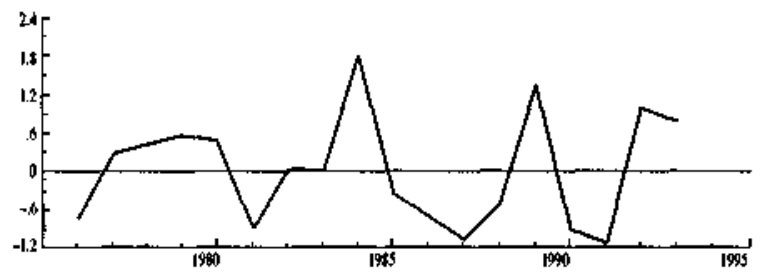

Fuente: Cálculos propios.

\section{V}

\section{Componentes tendenciales, cíclicos y}

\section{discrecionales de las finanzas públicas en Chile}

Entre fines de los años setenta y fines de los ochenta el sector público chileno redujo significativamente su tamaño relativo, de cerca de $40 \%$ a menos del $30 \%$ del PIB. Las privatizaciones de empresas públicas y de la seguridad social y el control del gasto público permitieton afrontar la crisis de los años ochenta con déficit relativamente moderados. Desde 1988 a la fecha se han obtenido importantes excedentes en las cuentas públicas (gráfico 2); la política fiscal, a pesar de su menor importancia relativa, ha hecho aportes significativos a la generación de ahorro interno y a los procesos de estabilización de la economía.

La notable disminución del superávit del sector público que se observa en los últimos años sugiere que la política fiscal ha sido menos estricta o más permisiva a partir de la instauración de la democracia en 1990. El análisis que sigue muestra, por el contrario, que una vez que se corrige este resultado mediante la eliminación de las principales variaciones exógenas de los gastos e ingresos públicos, se observa una orientación claramente restrictiva de la política fiscal.

El cuadro 1 muestra la evolución de las cuentas del gobierno central de Chile en 1989-1993. En él el superávit global se calcula sin considerar los aportes del FCC, mecanismo que compensa las fluctuaciones entre el precio del cobre previsto para el ejercicio presupuestario y el precio efectivo. ${ }^{6}$ Por ejemplo, en 1989

- El superávit efectivo es entonces el superávit global más los depósitos devengados en el FCC. 
GRAFKCO 2

Chife: Saldo global del gobierno central

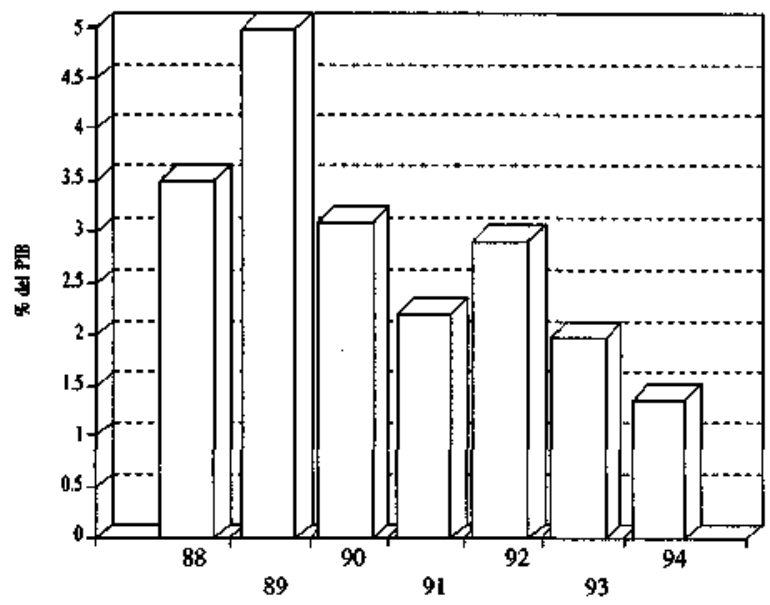

Fuente: cuadro 1.

la bonanza de este metal aportó al sector público casi cuatro puntos de PIB, ingresos que se contabilizaron en el FCC y no formaron parte del presupuesto regular. La existencia de este fondo reduce fuertemente la volatilidad de los ingresos y del saldo de las cuentas públicas. Esta es la principal fuente exógena de ingresos del sector público que no está vinculada con el ciclo económico interno. Por lo tanto, el cálculo del superávit que excluye los aportes de este fondo permite una aproximación más precisa de sus componentes cíclico y discrecional.

En cuanto a los restantes ingresos del sector público, los tributarios están directamente vinculados al ciclo económico, y los ingresos de operación, a su vez, dependen de las políticas de fijación de tarifas públicas. Las imposiciones previsionales y las transferencias corrientes están sometidas a la legislación en vigor, y no dependen directamente del nivel de actividad economica. Los ingresos por ventas de cobre están determinados por las fluctuaciones del precio del metal en el exterior y por la diferencia entre el precio previsto en la ley de presupuestos y el precio medio anual efectivo. Exceptuados los ingresos tributarios, los restantes no tienen una relación clara con el ciclo economico interno, aun cuando las partidas de ingresos de operación, de imposiciones previsionales y de otros ingresos son sensibles en alguna medida a la actividad económica.

Por el lado de los gastos, no puede suponerse en Chile una relacion significativa entre el ciclo de actividad y el gasto público, por cuanto las subvenciones al desempleo son reducidas. ${ }^{7}$ Si bien los restantes gastos públicos pueden tener una evolución más bien procíclica (en el sentido de que las mermas en el nivel de actividad y en la tributación llevan generalmente a ajustes de las partidas de gastos más flexibles en el corto plazo, como la compra de bienes y servicios o la inversión real), esta relación no es automática, ya que depende de decisiones discrecionales de la autoridad pública.

Por lo tanto, para calcular el indicador estructural de la oCDE para Chile sólo hay que estimar la elasticidad de la recaudación tributaria respecto del PIB, por cuanto éste es el único ingreso cíclico. Dada la ausencia de gastos asociados al ciclo económico, la magnitud del déficit cíclico en Chile, y probablemente en la mayoría de los países de la región, es bastante menor que en la $O C D E$, debido a la reducida significación de las prestaciones por desempleo.

El cálculo de los ingresos cíclicos para los años 1989-1993 (recuadro 1) toma en cuenta la estructura dinámica de la función tributaria estimada, lo que implica elasticidades distintas para cada año. Así, en el primen período la elasticidad corresponde a la de corto plazo. en el segundo año, se agrega a ésta el efecto de la variación de la diferencia entre el producto efectivo y el tendencial en el período anterior. Dicha estructura describe los efectos rezagados que tienen las variaciones cíclicas del producto sobre los ingresos tributarios: Como no se han identificado otros ingresos o gastos con componentes cíclicos, el superávit cíclico es exactamente igual a los ingresos ć́clicos (cuadro 2).

El ejercicio muestra con claridad la importancia del componente cíclico del superávit, que alcanza en algunos años a más de $20 \%$ del saldo observado (gráł fico 3). Los ciclos de la economía han tenido efectos significativos en las finanzas públicas; en los años de fuerte crecimiento, los ingresos tributarios transitorios representaron hasta un máximo de 0.4 puntos del PiB: A la inversa, el ajuste de 1990 significó una merma de los ingresos fiscales respecto de su tendencia du; rante dos períodos consecutivos.

El indicador de superávit estructural, o más pre cisamente las variaciones de este superávit, permiten calificar la orientación de la política fiscal. Las varia ciones del superávit estructural son relativamente le ves, puesto que no alcanzan a un punto del PIB en el

\footnotetext{
7 Tal relación existió sin embargo en el pasado; durante la etapa de desempleo masivo a príncipios de los años ochenta se llevaron a cabo programas de empleo de emergencia que desaparecieron medida que se redujo la tasa de desocupación.
} 
CUADRO 1

Chile (goblemo central): Clasificación económica

(Porcentajes del producto interno bruto)

\begin{tabular}{|c|c|c|c|c|c|}
\hline & 1989 & 1990 & 1991 & 1992 & 1993 \\
\hline I. Ingreso total & 23.6 & 22.1 & 23.7 & 24.4 & 24,6 \\
\hline $\begin{array}{l}\text { 1. Ingresos corrientes } \\
\text { Ingresos de operacion } \\
\text { Imposiciones previsionales } \\
\text { Ingresos tributarios netos } \\
\text { Cobre neto de FCC } \\
\text { Transferencias } \\
\text { Otros ingresos }\end{array}$ & $\begin{array}{r}21.3 \\
1.7 \\
1.7 \\
14.8 \\
1.9 \\
0.2\end{array}$ & $\begin{array}{r}20.7 \\
1.5 \\
1.7 \\
14.6 \\
1.6 \\
0.2\end{array}$ & $\begin{array}{r}22.6 \\
1.7 \\
1.6 \\
16.9 \\
1.1 \\
0.1\end{array}$ & $\begin{array}{r}23.2 \\
1.6 \\
1.6 \\
17.5 \\
1.3 \\
0.1\end{array}$ & $\begin{array}{r}23.6 \\
1.6 \\
1.6 \\
18.4 \\
0.7 \\
0.2\end{array}$ \\
\hline $\begin{array}{l}\text { 2. Ingresos de capital } \\
\text { Venta de activos } \\
\text { Físicos } \\
\text { Financieros } \\
\text { Recuperación de préstamos }\end{array}$ & $\begin{array}{l}2.4 \\
1.8 \\
0.2 \\
1.6 \\
0.6\end{array}$ & $\begin{array}{l}1.5 \\
0.9 \\
0.2 \\
0.8 \\
0.6\end{array}$ & $\begin{array}{l}1.2 \\
0.6 \\
0.2 \\
0.4 \\
0.6\end{array}$ & $\begin{array}{l}1.1 \\
0.6 \\
0.1 \\
0.5 \\
0.5\end{array}$ & $\begin{array}{l}1.0 \\
0.4 \\
0.1 \\
0.4 \\
0.6\end{array}$ \\
\hline II. Gasto total & 21.8 & 21.3 & 22.2 & 22.1 & 22.6 \\
\hline $\begin{array}{l}\text { 1. Gastos corrientes } \\
\text { Personal } \\
\text { Bienes y servicios } \\
\text { Prestaciones previsionales } \\
\text { Intereses de la deuda pública } \\
\text { Interna } \\
\text { Exterma } \\
\text { Transferencias } \\
\text { Otros }\end{array}$ & $\begin{array}{r}18.2 \\
3.6 \\
1.9 \\
6.2 \\
1.7 \\
0.5 \\
1.2 \\
4.7 \\
0.1\end{array}$ & $\begin{array}{r}18.2 \\
3.7 \\
1.9 \\
6.3 \\
1.9 \\
0.6 \\
1.4 \\
4.2 \\
0.1\end{array}$ & $\begin{array}{r}18.8 \\
3.8 \\
2.0 \\
6.2 \\
2.2 \\
0.9 \\
1.3 \\
4.5 \\
0.1\end{array}$ & $\begin{array}{r}18.1 \\
3.8 \\
2.0 \\
6.1 \\
1.4 \\
0.4 \\
1.0 \\
4.7 \\
0.1\end{array}$ & $\begin{array}{r}18.5 \\
4.0 \\
2.0 \\
6.3 \\
1.3 \\
0.4 \\
0.9 \\
4.8 \\
0.2\end{array}$ \\
\hline $\begin{array}{l}\text { 2. Gastos de capital } \\
\text { Inversión real } \\
\text { Inversion financiera } \\
\text { Transferencias de capital }\end{array}$ & $\begin{array}{l}3.6 \\
2.1 \\
0.9 \\
0.6\end{array}$ & $\begin{array}{l}3.1 \\
2.0 \\
0.8 \\
0.3\end{array}$ & $\begin{array}{l}3.3 \\
2.3 \\
0.8 \\
0.2\end{array}$ & $\begin{array}{l}4.0 \\
2.6 \\
1.0 \\
0.3\end{array}$ & $\begin{array}{l}4.1 \\
3.0 \\
0.8 \\
0.2\end{array}$ \\
\hline Superávit en cuenta corrlente (I.1-II.1) & 3.0 & 2.5 & 3.7 & 5.1 & 5.0 \\
\hline Superávit global (I-I) & 1.8 & 0.8 & 1.6 & 2.3 & 2.0 \\
\hline $\begin{array}{l}\text { Partidas informativas } \\
\text { Depositos devengados } \\
\text { en el } \mathrm{FCC}^{\mathrm{a}}\end{array}$ & 3.8 & 2.3 & 0.7 & 0.3 & .0 .2 \\
\hline $\begin{array}{l}\text { Uso del FEpp } \\
\text { Amortizaciones de la } \\
\text { deuda pública }\end{array}$ & $6 . \overline{8}$ & $2 . \overline{4}$ & $\begin{array}{l}0.2 \\
2.1\end{array}$ & $1 . \overline{7}$ & $\begin{array}{r}-0.1 \\
2.1\end{array}$ \\
\hline
\end{tabular}

Fuente: Chile, Gobierno de (1989, 1990, 1991, 1992 y 1993).

a FC: Fondo de Compensación del Cobre.

b FePP: Fondo de Estabilización de los Precios del Petróleo.

CUADRO 2

Chile: Superávit cíclico y superávit estructural (Porcentajes del PIB)

\begin{tabular}{|c|c|c|c|c|c|}
\hline & 1989 & 1990 & 1991 & 1992 & 1993 \\
\hline $\begin{array}{l}\text { Ingresos tributarios cíclicos } \\
\text { Ingresos tributarios estructurales }\end{array}$ & $\begin{array}{r}0.40 \\
14.43\end{array}$ & $\begin{array}{l}-0.17 \\
14.77\end{array}$ & $\begin{array}{l}-0.41 \\
17.36\end{array}$ & $\begin{array}{r}0.22 \\
17.32\end{array}$ & $\begin{array}{r}0.34 \\
18.07\end{array}$ \\
\hline $\begin{array}{l}\text { Superavit observado } \\
\text { Variaciones }\end{array}$ & 1.80 & $\begin{array}{r}0.84 \\
-0.96\end{array}$ & $\begin{array}{l}1.55 \\
0.71\end{array}$ & $\begin{array}{l}2.29 \\
0.74\end{array}$ & $\begin{array}{r}1.99 \\
-0.30\end{array}$ \\
\hline $\begin{array}{l}\text { Superavit cfclico } \\
\text { Variaciones } \\
\text { Porcentaje del superávit observado }\end{array}$ & $\begin{array}{r}0.40 \\
22.22\end{array}$ & $\begin{array}{l}-0.17 \\
-0.57 \\
20.24\end{array}$ & $\begin{array}{r}-0.41 \\
-0.24 \\
26.45\end{array}$ & $\begin{array}{l}0.22 \\
0.63 \\
9.61\end{array}$ & $\begin{array}{r}0.34 \\
0.12 \\
17.09\end{array}$ \\
\hline $\begin{array}{l}\text { Superávit estructural } \\
\text { Variaciones }\end{array}$ & 1.41 & $\begin{array}{r}1.01 \\
-0.40\end{array}$ & $\begin{array}{l}1.96 \\
0.95\end{array}$ & $\begin{array}{l}2.06 \\
0.10\end{array}$ & $\begin{array}{r}1.65 \\
-0.41\end{array}$ \\
\hline
\end{tabular}

Fuente: Cálculos propios a partir del cuadro 1. 
GRAFICO 3

Chile: Componentes cíclico y estructural del superávit público

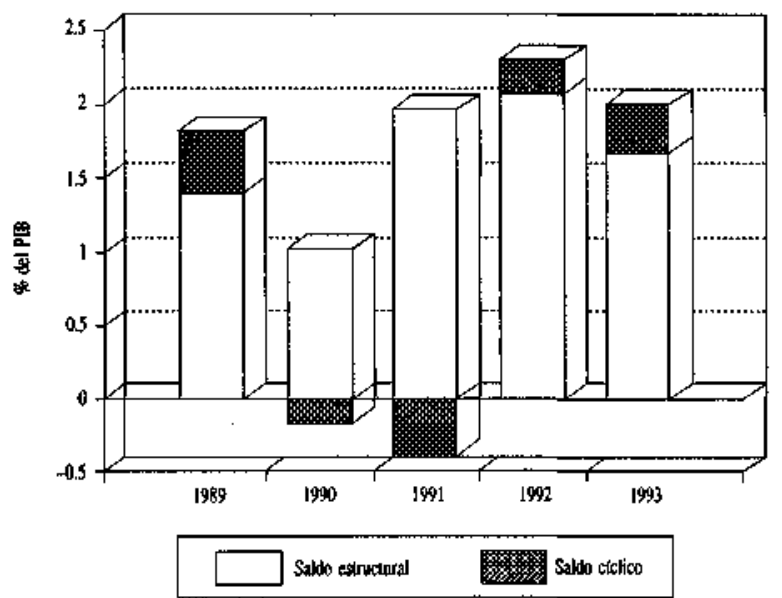

Fuente: cuadro 2.

período analizado. En efecto, la economía chilena no tuvo en 1989-1993 episodios significativos de ajuste ni tasas de crecimiento que superaran el sendero tendencial por más de un año. En la parte baja del ciclo (1990), el saldo estructural tendió a disminuir, en tanto que en la parte alta (1992-1993) el superavit estructural tendio a aumentar. Estas fluctuaciones reflejan el carácter anticíclico de la política fiscal en los años recientes (Marcel, 1993). Si bien esta orientación también se observa en el saldo efectivo, las magnitudes son muy diferentes (cuadro 1). Así, mientras el saldo fiscal fue mayor en 1992, el indicador estructural mostro una progresión inferior. Esta tendencia se manifestó también en 1993, año en que la disminución del superávit estructural fue mayor que la caída del déficit observado, mostrando que la posición favorable en el ciclo ocultaba una ligera degradación de las finanzas públicas en dicho año. Es importante destacar el rezago que existió entre el ciclo económico y las variaciones de los ingresos públicos (gráfico 4). Las oscilaciones del nivel de actividad se hicieron notar con mayor fuerza en el ejercicio presupuestario siguiente, debido al rezago en los plazos de recaudación tributaria. Así, por ejemplo, el impacto negativo del ajuste de 1990 fue mayor en 1991, año en que se recuperó la senda de crecimiento potencial. Asimismo, la alta tasa de crecimiento de 1992 tuvo efectos más favorables sobre el superávit en 1993.

El ejercicio identifica de esta manera con mayor precisión la orientación de la política fiscal. En general, es posible apreciar una tendencia anticíclica en el
GRAFICO 4

Chile: Ciclo económico y ciclo presupuestario

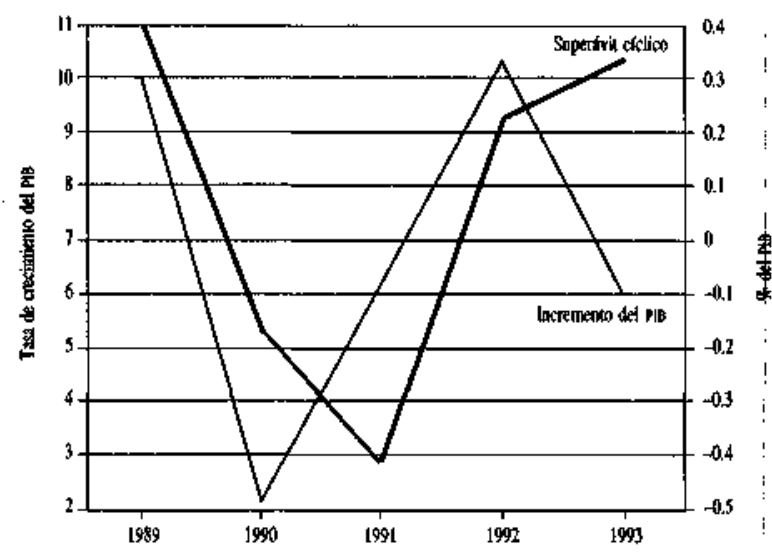

Fuente: cuadro 2.

manejo presupuestario, con mejoras significativas del superávit estructural en los períodos recientes de expansión del nivel de actividad. Pero también es interesante descomponer este superávit estructural en sus componentes tendencial y discrecional, para lo cual se calcula el indicador de impulso fiscal con la metodología del FMI. Para mostrar los resultados de este ejercicio en el caso de Chile (cuadro 3), nuevamente sir considerar componentes cíclicos en los gastos públicos, se tomó el año 1989 como base por ser el período de inicio del análisis, aunque no representa adecuada + mente un período neutro en términos fiscales, por el alto crecimiento que se registró en él.

Según el criterio del FMI, los ingresos son consi + derados neutros si su tasa de crecimiento es la misma que la del nivel de actividad. Según esta definición; en Chile los ingresos discrecionales aumentaron en un punto del PIB en 1992 y 1993. Si comparamos esto\$ resultados con los brindados por el indicador estructu: ral, observamos que los ingresos cíclicos fueron infe riores, puesto que éstos se calculan ahora a base de una elasticidad unitaria. Como corolario, hubo un aumento de los ingresos discrecionales. Además, debido a la posición favorable en el ciclo en 1992-1993, el Pls tendencial creció menos que el PIB efectivo, lo que di $\phi$ como resultado una compresión de los gastos e ingresos tendenciales y un incremento de los ingresos y gastos discrecionales, cuando éstos se calculan en relación al PIB efectivo. Según esta descomposición, y salv $\phi$ en 1990, la política fiscal ha tenido un comportamien. to neutro en los últimos años; inclusive, el indicador de impulso fiscal fue nulo en 1991 y 1993 (gráfico 5). 
CUADRO 3

Chile: Indicador de impulso flecal

\begin{tabular}{|c|c|c|c|c|c|}
\hline & 1989 & 1990 & 1991 & 1992. & 1993 \\
\hline Ingresos totales & 23.63 & 22.14 & 23.74 & 24.38 & 24.58 \\
\hline Ingresos tendenciales totales & 23.63 & 24.03 & 24.09 & 23.23 & 23.32 \\
\hline Ingresos cíclicos & - & -0.25 & .0 .29 & 0.25 & 0.20 \\
\hline Ingresos neutros & 23.63 & 23.78 & 23.80 & 23.48 & 23.52 \\
\hline Ingresos discrecionales & - & -1.64 & .0 .06 & 0.90 & 1.06 \\
\hline Gastos totales & 21.82 & 21.30 & 22.19 & 22.10 & 22.59 \\
\hline Gastos tendenciales & 21.82 & 22.19 & 22.25 & 21.45 & 21.53 \\
\hline Gastos discrecionales & - & 0.89 & 0.06 & 0.65 & 1.06 \\
\hline Superavit observado & 1.80 & 0.84 & 1.55 & 2.29 & 1.99 \\
\hline Superávit tendencial & 1.80 & 1.84 & 1.85 & 1.78 & 1.79 \\
\hline Superávit ćclico & - & -0.25 & .0 .29 & 0.25 & 0.20 \\
\hline Superávit neutro & 1.80 & 1.59 & 1.56 & 2.03 & 1.99 \\
\hline Impulso fiscal & - & -0.75 & - & 0.26 & - \\
\hline
\end{tabular}

Fuente: Cálculos propios a partir del cuadro 1.

La desagregación del superávit estructural en sus componentes tendencial y discrecional muestra que gran parte de éste se asocia a determinantes de tendencia. Según estos cálculos, la política fiscal en los años recientes no ha tenido en general intervenciones discrecionales, por lo que el sector público no ha representado una fuente de perturbación de los equilibrios macroeconómicos. Esto tiende a mostrar un manejo fiscal que busca evitar los ajustes procíclicos de las finanzas públicas y asegurar una senda tendencial sostenible del gasto público. La programación fiscal se ha estructurado en torno al crecimiento potencial de la economía más que en función de sus fluctuaciones cíclicas.

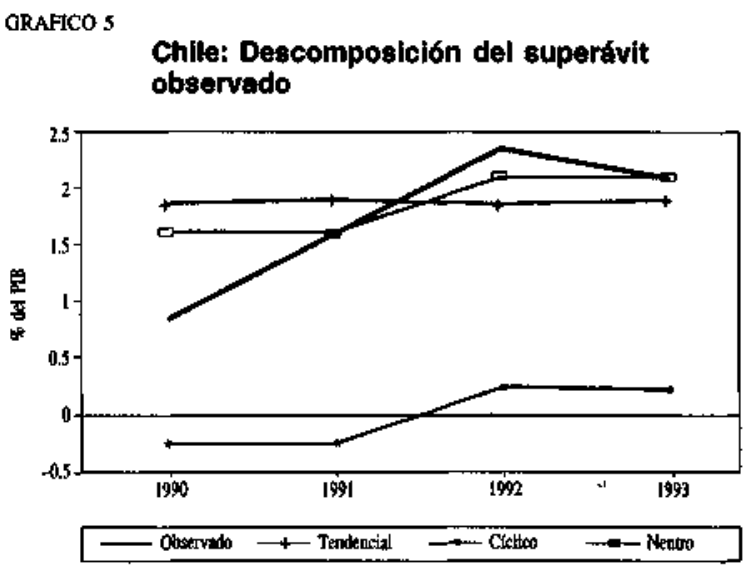

Fuente; cuadro 2.

\section{VI}

\section{Síntesis y conclusiones}

Dada la vulnerabilidad del presupuesto a las variaciones en el entorno macroeconómico, la gestión de las finanzas públicas requiere una adecuada evaluación de los recursos potenciales en el mediano plazo. Para ello, es necesario identificar los fenómenos transitorios que inciden en el presupuesto público. Los indicadores de discrecionalidad fiscal, en conjunto con otros instrumentos, permiten separar los componentes transitorios y permanentes de las cuentas públicas, y con ello ayudan a sustraer del análisis macroeconómico de la política fiscal, y de las decisiones de gastos $\mathrm{e}$ ingresos, las fuentes exógenas de los movimientos del presupuesto. En este caso, los indicadores utilizados permiten separar los componentes cíclicos y estructurales del saldo de las cuentas públicas.

Es deseable promover en este contexto el establecimiento de una norma de gasto público de mediano plazo, que permita formular reglas del juego claras que 
el Estado se compromete a respetar, y que asegure la eficacia de la acción pública; dicha norma debe ser compatible con la evolución deseada de las finanzas públicas a lo largo del ciclo. Esto induce a desarrollar mecanismos de programación plurianual compatibles con las restricciones estructurales de las economías y que aseguren al mismo tiempo una cierta continuidad en el accionar del Estado.

En el caso de Chile, la centralización de la autoridad fiscal permite evaluar la política fiscal a partir de la contabilidad del gobierno central. Además, la existencia del FCc, que separa en las cuentas públicas los efectos de los movimientos no previstos del precio del cobre, y la indexación de los impuestos a la inflación permiten elaborar indicadores que miden adecuadamente la orientación de la política fiscal.
La aplicación de indicadores de discrecionalidad fiscal al caso de Chile ha permitido una medición más precisa de la política fiscal de este país en los últimos años. En general, es posible apreciar una tendencia anticíclica en el manejo presupuestario, con disminuciones del componente estructural en años de menor crecimiento y con mejoras significativas del superávit estructural en los períodos recientes de expansión del nivel de actividad. Esto deriva de la aplicación de una programación fiscal que se estructura en torno a la senda de crecimiento tendencial de la economía y que evita ajustes de magnitud según los vaivenes de la coyuntura. De hecho, la trayectoria del saldo público ha sido neutra en los últimos años, ya que las tasas de crecimiento de los gastos e ingresos públicos han coincidido con el incremento del PIB tendencial.

\section{Bibliografía}

Blanchard, O.J., J.C. Chouraqui, R.P. Hagemann y N. Sartor (1990); The sustainability of fiscal policy: New answers to an old question, OECD Economic Srudies, N 15, París, Organización de Cooperación y Desarrollo Económicos (OCDE).

Buiter, W.(1988): Some Thoughts on the Role of Fiscal Policy in Stabilization and Structural Adjustment in Developing Countries, NBER Working Paper, $\mathrm{N}^{\circ} 2603$, Cambridge, Massachusetts, Oficina Nacional de Investigaciones Económicas.

Carcioli, R., G. Barris y O. Cetrángolo (1994): Reformas tributarias en América Latina. Analisis de experiencias durante la década de los años ochenta, Santiago de Chile, CEPAL.

CEPAL (Comisión Económica para América Latina y el Caribe (1994): Las finanzas públicas, Estudio Económico de América Latina y el Caribe 1993. Vol. I, LC/G. 1833-P, Santiago de Chile, diciembre, Publicación de las Naciones Unidas, $\mathrm{N}^{\circ}$ de venta S.94.JI.G.2.

Chand, S.K.(1992); Fiscal Impulses and their Fiscal Impact, IMF Working Paper, N 38, Washington, D. C., Fondo Monetario Internacional (FMI), mayo.

Chile, Gobieno de (1989 a 1993): Estadísticas de las finanzas públicas (publicaciones anuales), Santiago de Chile, Ministerio de Hacienda, Dirección de Presupuesto.

Chouraqui, J. C., B. Jones y R.B. Montador (1986): Public debt in a medium-term perspective, OCDE Economic Studies, $\mathrm{N}^{\circ} 7$, París, OCDE.

Creel, J. y H. Sterdyiniak (1995): Les déficits publics en Europe. Causes, consequences on rémèdes a la crise?, Revue Economique, vol. 46, $\mathrm{N}^{\diamond} 3$, París, Presses de la Fondation Nationale des Sciences Politiques.
Fernandez, M., M. Nadal y J. Sanz (1993): Indicadores de discrecionalidad fiscal: metodologias alternativas, Documentos de trabajo, Madrid, Dirección General de Planificación. Secretaría de Estado de Hacienda, junio.

Gramlich, E. (1990): Fiscal Indicators, OECD Working Paper\$, $\mathrm{N}^{\circ}$ 80. París, OCDE,

Heller, P., R. Haas y A. Mansur (1986): A Review of the Fiscal Impulse Measure, Occasional Paper, $N^{\circ} 44$. Washington D.C., FMI, mayo.

Marcel, M. (1991): Elaboración del marco macroeconómico del presupuesto, seminario $\mathrm{El}$ presupuesto frente a los nuevos retas de la planificación y coordinación de políticas públicas. México, D.F., Agencia Española de Cooperación Intemacional (AECI)/Instituto Latinoamericano y del Caribe de Planificación Económica y Social (ILPES), agosto.

(1993): Gobernabilidad fiscal, presupuestos y finanzas públicas: un estudio a partir de la experiencia chilena, Wasbington D.C., Banco Interamericano de Desarrollo (BID), mimeo.

Martín, J.M. y A. Núfez del Prado (1993): Gestión estratégich, planificación y presupuesto, Revista de la CEPAL, $\mathrm{N}^{\circ} 49$, LC/G. 1757 $\times$, Santiago de Chile, CEPAL, abril.

Martmer, R. (1995): Indicadores de la política fiscal: diseño y aplicaciones en América Latina, LCIP/R.151/Rev.1, Santiago de Chile, CEPAL/ILPES, 8 de mayo.

Molinas, C. (1994): Déficit cíclico y déficit estructural, Presupuesto y gasto público, $\mathrm{N}^{\circ} 12$, Santiago de Chile, Instituto de Estudios Fiscales, Ministerios de Economía y de Haciendi.

oCDE (Organización de Cooperación y Desartollo Económicos) (1993): OECD Economic Outlook, $\mathrm{N}^{\circ}$ 53, París, junio. 